\title{
Sources and historical sedimentary record: Temporal variability of $n$-alkane and PAHs from the Yellow River Estuary, China
}

\author{
Chuanyuan Wang a,b,", Liangju Yu ${ }^{\mathrm{a}, \mathrm{b}}$, Yanmei Zou ${ }^{\mathrm{a}}$, Ling $\mathrm{Ji}^{\mathrm{c}}$, Yuanwei $\mathrm{Li}^{\mathrm{a}}$ \\ ${ }^{\text {a }}$ Key Laboratory of Coastal Environmental Processes and Ecological Remediation, Yantai Institute of Coastal Zone Research, Chinese Academy of Sciences, Yantai, \\ 264003, PR China \\ benter for Ocean Mega-Science, Chinese Academy of Sciences, Qingdao, 266071, PR China \\ ${ }^{\mathrm{c}}$ Yantai Marine Environment Monitoring Center Station, State Oceanic Administration, Yantai, 264006, PR China
}

\section{A R T I C L E I N F O}

Editorial handling by Prof. X. Li

\section{Keywords:}

Sediment core

SPM

n-Alkane

PAHs

Yellow river estuary

Historical sedimentary record

\begin{abstract}
A B S T R A C T
The composition and distribution of $n$-alkanes and polycyclic aromatic hydrocarbons (PAHs) in suspended particulate matter (SPM) from the Yellow River and a sedimentary core from the Yellow River Estuary, China, were measured in order to determine environmental changes in the Yellow River Estuary on a regional scale. The concentration of $n$-alkane in SPM increased along the upper-middle-lower reaches of the Yellow River. The total concentrations of $n$-alkanes and PAHs in the core ranged from 0.04 to $0.86 \mu \mathrm{g} \mathrm{g}^{-1}$ (avg. $0.21 \mu \mathrm{g} \mathrm{g}^{-1}$ ), and from 0.04 to $0.29 \mu \mathrm{g} \mathrm{g}^{-1}$ (avg. $0.15 \mu \mathrm{g} \mathrm{g}^{-1}$ ) on a dry wt. basis, respectively. Understanding the temporal evolution of $n$ alkanes provide information on terrigenous versus aquatic productivity, oil exploration at the Shengli Oilfield, and channel diversion in the Yellow River. $n$-Alkanes in SPM were mainly derived from mixed sources, with terrigenous inputs dominating. PAHs in the sediment core were predominantly derived from coal and biomass combustion. The variation in PAHs levels throughout the core determines changes in energy use and socioeconomic development. The temporal variability in $n$-alkane and PAHs and their molecular diagnostic ratios revealed a trend of regional environmental change and the role of anthropogenic activity in that environmental change.
\end{abstract}

\section{Introduction}

Estuaries are highly productive and dynamic transitional ecosystem, which linked continental and marine environments. The Yellow River is the second largest river in China and the sixth largest river in the world. As the most sediment-laden large river in the world, the Yellow River carries a huge amount of sediments to the Bohai Sea every year. The Yellow River Delta (YRD) is the youngest wetland in the warm temperate zone of China (Yang et al., 2009), with the fastest growth and most dramatically changing landscape. Since 1855, the lower reaches of the Yellow River have been frequently diverted by breaches due to the effect of natural and human factors. The current course was formed by the last diversion in 1996. Located on the YRD, the Shengli Oilfield is the second largest oilfield in China. Development in the YRD has been rapid over the past 40 years due to exploitation of the Shengli Oilfield. Exploitation of the Shengli Oilfield and the Yellow River diversion affected the input and deposition of organic matter in the delta.

Estuarine sediments are a major reservoir of aliphatic hydrocarbons and polycyclic aromatic hydrocarbons (PAHs) from both anthropogenic input (vehicle exhaust, petroleum and industrial releases) and natural input (aquatic organisms, plankton, and terrestrial plants) (Boitsov et al., 2009). Because of their toxic, carcinogenic, and mutagenic, PAHs have given considerable attention by scientists, governments, and the public (Machado et al., 2014). Although $n$-alkane only account for a small fraction of aliphatic hydrocarbons, their composition may provide efficient information on the source and maturity of aliphatic hydrocarbons by their parent precursors (Kaiser et al., 2014; Wang et al., 2017). The distribution of $n$-alkanes in rivers can reflect many natural processes occurring on the surface of the basin, such as geomorphological, ecological and hydrological processes. Suspended particulate matter (SPM) is the main carrier of organic pollutants in the river transport process, which may provide basic scientific data on the migration and transformation of $n$-alkanes in sediment of the Yellow River Estuary (YRE). To clearly understand the biogeochemical cycling and fate of terrigenous organic matter (OM), the factors and processes controlling the sources and distribution of $\mathrm{OM}$ in estuarine sediments must be

\footnotetext{
* Corresponding author. Yantai Institute of Coastal Zone Research, Chinese Academy of Sciences, PR China.

E-mail address: cywang@yic.ac.cn (C. Wang).
} 


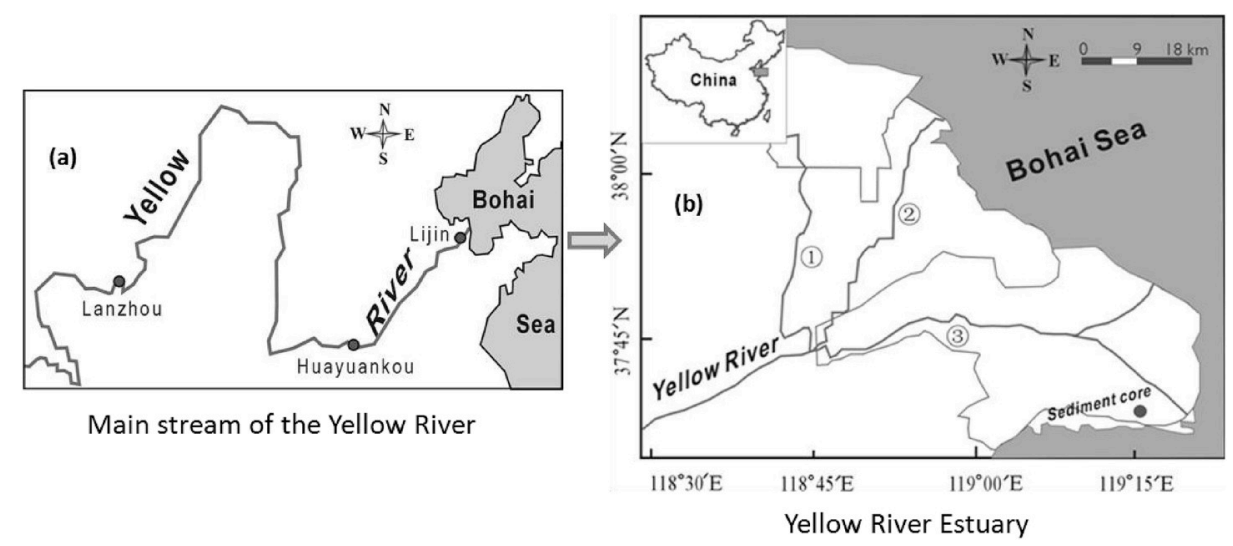

Fig. 1. Sampling sites in the Yellow River (a) and Yellow River Estuary (b).

Note: (1)Diaokou Course (1964-1976); (2)Shenxiangou Course (1953-1964); (3)Qingshuigou Course (1996-present).

known (e.g., Thornton and McManus, 1994; Middelburg and Herman, 2007; Ankit et al., 2017). Therefore, it is important to study the concentration, spatial distribution and source of aliphatic hydrocarbons and PAHs in marine sediments, especially in estuarine sediments, for evaluating the impact of sediment pollution and human activities. Most studies investigating pollutants in the YRD have focused on hydrocarbons, PAHs, polychlorinated biphenyls (PCBs), and trace metals (e.g., Chen et al., 2007; Yang et al., 2009; Wang et al., 2011; Li and Li, 2017). For example, with respect to PAHs, multivariate statistical analysis has shown that PAHs in surface soils of the YRD have been principally derived from coal and biomass combustion, petroleum spills, and/or vehicular emissions (Yuan et al., 2014). The Yellow River is one of the most important conduits for transporting sediments and pollutants from land to sea in northern China. However, to the best of our knowledge, reporting on the temporal trends and sources of $n$-alkane and PAHs in sediment cores from the Yellow River Delta is sparse.

Molecular biomarkers, such as $n$-alkanes and PAHs, not only contribute to the understanding the origin and diagenetic evolution of organic matter, but can also provide a historical record of human activities. Several $n$-alkane indices have been developed to identify sources of organic matter (OM) in environments characterized by complex sources (eg. contribution from terrestrial/aquatic sources, petrogenic sources). PAHs are good indicators of human activities, and their content changes are closely related to regional energy consumption, industrialization level and urbanization process. This study was designed to (i) analyze the composition and regional differences in $n$ alkanes contained SPM from the Yellow River in order to study the migration and transformation of $n$-alkanes in the YRD; (ii) reveal the historical variability in $n$-alkane and PAHs sources with a the sediment core from the YRE to investigate the correlation between anthropogenic activity and environmental change, and (iii) discuss the effects of exploiting the Shengli Oilfield and relocating the course of the Yellow River on the hydrocarbon sources in YRE. The results of this study provide valuable insights into the role of anthropogenic activities in environmental change and a reliable base for further studies of organic pollutants in the region.

\section{Material and methods}

\subsection{Sample collection}

Water samples were collected in October 2014 from the upper stream (Lanzhou Hydrological Station, LZ), middle stream (Huayuankou Hydrological Station, HYK), and lower reaches (Lijin Hydrological Station, LJ) of the Yellow River (Fig. 1a). The Lijin Hydrological Station is the last hydrological station before the Yellow River enters the Bohai Sea (Wang et al., 2018). Water samples were carried out in October autumn (dry season) to reduce the impact of floods and rainfall. The sample was taken from each location three times and mixed to represent a sample from a sampling station. The water sample was filtered on site through a $0.7-\mu \mathrm{m}$ glass-fiber membrane (GF/F, Whatman, England). About $1 \mathrm{~L}$ of water samples was filtered through a pre-combusted (Whatman $0.7-\mu \mathrm{m}$ $\mathrm{GF} / \mathrm{F}$ ) filter at $300^{\circ} \mathrm{C}$ for $6 \mathrm{~h}$ at low vacuum condition and dried at $60^{\circ} \mathrm{C}$ for at least $24 \mathrm{~h}$. Filters were acid fumigated for $12 \mathrm{~h}$ in the desiccators to remove inorganic carbon.

The sediment core was collected from the Yellow River Estuary in July 2015 (Fig. 1b), using a gravity corer. It was sectioned into $2 \mathrm{~cm}$ interval segments using a stainless steel cutter. The sectioned samples and glass-fiber membranes mentioned above, were packed in aluminum foil, and transported to the laboratory within $48 \mathrm{~h}$ and frozen at $-20{ }^{\circ} \mathrm{C}$ until analysis.

\subsection{Sediment dating}

The dating of the sediment core was conducted using radionuclide measurement. The detailed methods about ${ }^{210} \mathrm{~Pb}$ dating have been reported (Hu et al., 2011; Wu et al., 2015). Briefly, ${ }^{210} \mathrm{~Pb}$ and ${ }^{226} \mathrm{Ra}$ activities were measured using an Ortec HPGe GWL series well-type coaxial low background intrinsic germanium detector. About $5.0 \mathrm{~g}$ of screened samples were place in a special test box for 15 days, so that uranium, radium and their short-lived daughters can be balanced. And then, the samples were measured in HPGe probe more than $36 \mathrm{~h}$, and the gamma-ray spectrum was obtained. The activity of the excess ${ }^{210} \mathrm{~Pb}$ was calculated by subtraction of the ${ }^{226} \mathrm{Ra}$ activity from the total ${ }^{210} \mathrm{~Pb}$ activity. The entire core $(42 \mathrm{~cm})$ covered the period from 1934 to 2015, and the average sedimentation rate was ca. $0.46 \mathrm{~cm} / \mathrm{yr}$.

\subsection{Sample extraction, separation and GC-MS analysis}

The procedure used in the present study for sample extraction and extract purification and fractionation of PAHs was modified from previous studies (Yang et al., 2009; Yuan et al., 2014). Freeze-dried sediments $(\sim 10 \mathrm{~g})$ were ground and homogenized by a mortar and pestle. After grinding, the sediments samples were packed with clean filter (paper was extracted) and extracted by the Soxhlet method. The glass-fiber membranes mentioned above and sediment samples were extracted using soxhlet apparatus with $n$-hexane/dichloromethane $(50 / 50)$ for $48 \mathrm{~h}$. The extract was concentrated to about $1 \mathrm{~mL}$ on a rotating evaporator, $10 \mathrm{~mL}$ of $\mathrm{n}$-hexane was added, and then concentrated to 1-2 mL to convert the solvent. Solvent replacement concentrate was purified by adding silica gel alumina purification column. The glass chromatography column was packed with activated at $150{ }^{\circ} \mathrm{C}$ after Soxhlet extraction (100-200 mesh). The column was first eluted with $n$-hexane to remove aliphatic hydrocarbons and then with mixed 


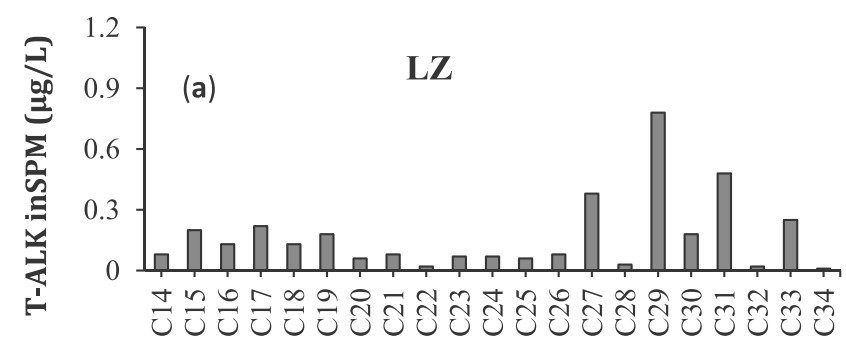

Carbon number

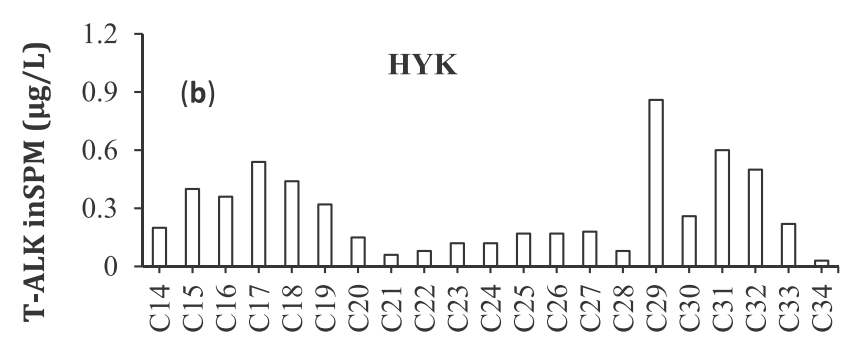

Carbon number

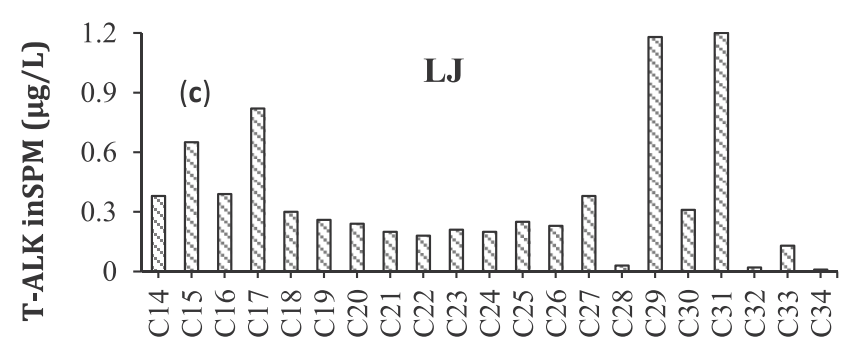

Carbon number

Fig. 2. Distribution of $n$-alkanes in SPM in the upper (a), middle (b), and lower reaches (c) of the Yellow River.

dichloromethane and $n$-hexane (1:1, v/v) for PAHs.

$n$-Alkane and PAHs were determined using an Agilent 7890A gas chromatography (GC) coupled to a 5975C mass selective detector (MS) equipped with a HP-5 MS capillary column (Specification: $30 \mathrm{~m} \times 0.25$ $\mathrm{mm}$ i.d. $\times 0.25 \mu \mathrm{m}$ film thickness). Samples were injected in splitless mode and Helium was used as the carrier gas. The injection temperature was $280^{\circ} \mathrm{C}$. The column temperature was programmed to ramp from 80 ${ }^{\circ} \mathrm{C}$ (held for $1 \mathrm{~min}$ ) to $280{ }^{\circ} \mathrm{C}$ at a rate of $5{ }^{\circ} \mathrm{C} \mathrm{min}{ }^{-1}$, and held at $280{ }^{\circ} \mathrm{C}$ for $12 \mathrm{~min}$. Quantitative analysis of $n$-alkanes and aromatics was carried out by internal standard method and six-point standard calibration curve method. Individual $n$-alkanes were identified based on the retention time of the authentic standards $\left(n \mathrm{C}_{10-40}\right.$, Sigma). The relative abundance was calculated from respective mass chromatogram peak areas. Alternately, each target PAHs were quantified based on the retention time and the $m / z$ ratio of an authentic PAH mixed standard (Sigma). Five surrogate standards (naphthalene-d8, phenanthrene-d10, dibenzothiophene-d10, fluoranthene-d10, and pyrene-d10) were added to all the samples to monitor the matrix effects. The quantification of each individual PAH was calculated based on six-point calibration curves.

\subsection{Quality assurance and quality control (QA\&QC)}

Procedural blanks, spiked blanks, spiked matrixes, and parallel samples were performed to control data quality. The recoveries of standard addition for the analysis of $n$-alkanes are $78.6 \% \sim 96.3 \%$. As for PAHs, the recoveries ranged from 86 to $108 \%$ for all 16 target analytes. Analysis of the blanks confirmed that there was no introduced
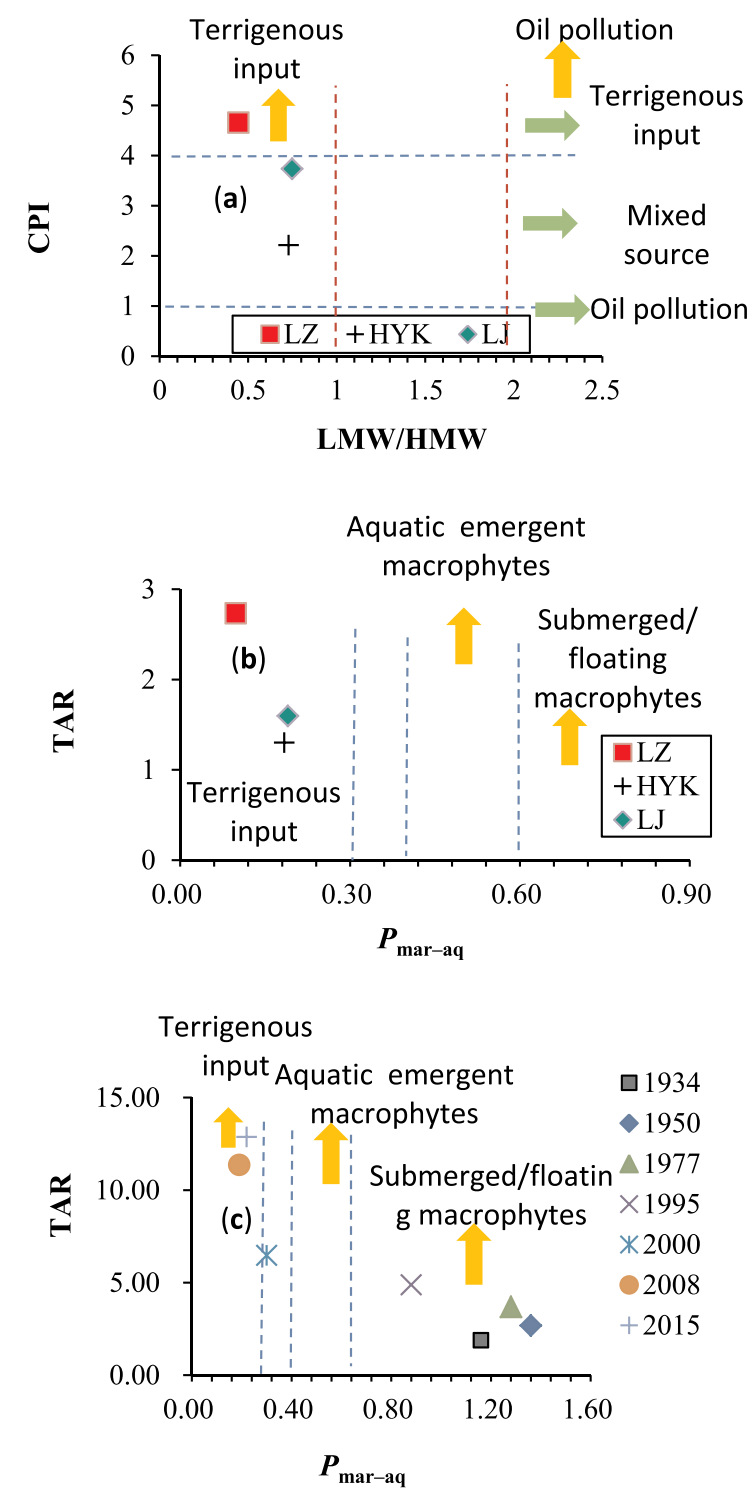

Fig. 3. Cross-plot of (a) CPI and LMW/HMW in SPM from Yellow River, (b) TAR and $P_{\text {max-aq }}$ in SPM from Yellow River, and (c) TAR and $P_{\text {max-aq }}$ in the sediment core from the Yellow River Estuary. (For interpretation of the references to colour in this figure legend, the reader is referred to the Web version of this article.)

Note: $\mathrm{CPI}=\left[\Sigma\left(\mathrm{C}_{25}-\mathrm{C}_{33}\right)\right.$ odd $/ \Sigma\left(\mathrm{C}_{24}-\mathrm{C}_{32}\right)$ even $+\Sigma\left(\mathrm{C}_{25}-\mathrm{C}_{33}\right)$ odd $/ \Sigma\left(\mathrm{C}_{26}-\right.$ $\mathrm{C}_{34}$ )even]/2; LMW/HMW: $\quad \Sigma<\mathrm{C}_{21} / \Sigma>\mathrm{C}_{23} ; \quad P_{\max -\mathrm{aq}}=\left(\mathrm{C}_{23}+\mathrm{C}_{25}\right) /$ $\left(\mathrm{C}_{23}+\mathrm{C}_{25}+\mathrm{C}_{31}+\mathrm{C}_{33}\right) ; \mathrm{TAR}=\left(\mathrm{C}_{27}+\mathrm{C}_{29}+\mathrm{C}_{31}\right) /\left(\mathrm{C}_{15}+\mathrm{C}_{17}+\mathrm{C}_{19}\right)$.

contamination or other interference over the whole experiment. The relative standard deviation was $<5 \%$, indicating good repeatability.

\section{Results and discussion}

3.1. Regionality of n-alkanes in suspended particles in the main river of the Yellow River

\subsubsection{Distribution of n-alkanes in SPM}

Understanding the regional differences in $n$-alkanes contained in SPM along the Yellow River and their distribution and possible sources, can provide a foundation for the study of $n$-alkane migration and transformation in surface water, surface sediments and sediment profiles in the Yellow River Estuary. Given the low concentrations of PAHs suspended in the water column, only the distribution of $n$-alkanes is 
discussed in this study. The concentration of total $n$-alkanes (T-ALK) in SPM from the mainstream of the Yellow River increased from upstream to downstream (Fig. 2). The total concentration of $n$-alkanes measured in the downstream was the highest concentration measured throughout the entire Yellow River basin. The downstream concentration is likely the combined result of $n$-alkane inputs to the upper and middle reaches of the Yellow River basin from biological production and inputs from tributaries in the downstream reach.

\subsubsection{Potential sources of $n$-alkanes in $S P M$}

Based on the distributions of $n$-alkanes, the carbon preference index (CPI) (Hedges and Prahl, 1993; Ankit et al., 2017) and the low-molecular-weight to high-molecular-weight ratio (LMW/HMW) have been introduced to indicate $n$-alkane maturity, sedimentary environment, source and other information (Bush and McInerney, 2013). The distribution of $n$-alkanes in SPM from the Lanzhou Hydrological Station in upper Yellow River was characterized by an obvious back peak with odd carbon number dominance. $\mathrm{C}_{17}$ was the main peak of the low carbon number portion, which also had weak odd-even predominance, indicating that the low carbon number portion may come from algae or bacteria. Algae and bacteria are common sources of low carbon $n$-alkanes in the upper reaches of the Yellow River. The LMH/HMW ratio of $n$-alkanes in SPM from the Lanzhou Hydrological Station was 0.44. High carbon $n$-alkanes mainly come from terrestrial plants, suggesting that the $n$-alkanes in SPM from the upper reaches of the Yellow River are mainly affected by terrestrial sources. The upper stream of the Yellow River that runs through Lanzhou spans the first and second steps of China's terrain, with a large drop and obvious erosion from running water, but with a high rate of vegetation cover. Because of this special hydrology and geomorphology, $n$-alkanes in SPM from Huayuankou Hydrological Station mainly consisted of high terrestrial plant inputs. With respect to the middle stream, the distribution of $n$-alkanes showed a more obvious bimodal distribution pattern. The LMH/HMW ratio increased from 0.44 to 0.60 relative to the upper stream (Fig. 3a). The distribution characteristics of $n$-alkanes in SPM from Lijin Station were similar to those from the middle stream of the Yellow River, also showing an obvious bimodal distribution with an LMH/HMW ratio of 0.75. Compared with the upstream, the increased LMW/HMW ratio indicates that the low carbon number $n$-alkane content increased, especially $\mathrm{C}_{15}$ and $\mathrm{C}_{17} n$-alkanes (Fig. 2). In this study, the average LMW/HMW values for SPM (3.53) were higher than 3, which is the characteristic of higher plant waxes.

The TAR, which is the ratio between the concentration of short-chain and long-chain $n$-alkanes, can be used to evaluate the relative contributions of $n$-alkanes from marine and terrestrial sources. This study showed a TAR ratio $>1$ for all studied locations (Fig. 3b), affirming the source of $n$-alkanes as debris of higher terrestrial plants (Bourbonniere and Meyers, 1996). The $P_{\text {mar-aq }}$ represents the ability to differentiate submerged/floating aquatic macrophytes from emergent and terrestrial plant sources (Ficken et al., 2000; Nemr et al., 2016). Low SPM $P_{\text {mar-aq }}$ values $(0.01-0.3)$ correspond to terrestrial plants.

$n$-Alkanes from algae and microorganisms are dominated by low carbon numbers, mainly $\mathrm{C}_{15}, \mathrm{C}_{17}$ and $\mathrm{C}_{19}$. Therefore $\left(\mathrm{C}_{15}+\mathrm{C}_{17}+\mathrm{C}_{19}\right) \%$ can be used to represent the contribution of aquatic sources. It showed that $(\mathrm{C} 15+\mathrm{C} 17+\mathrm{C} 19) \%$ increased from upstream $(17.09 \%)$ to downstream (22.85\%), which indicates that aquatic sources become more dominant moving from upstream to downstream while terrestrial sources become less dominant.

\subsection{Distribution of n-alkanes in the sediment core and historical sedimentary record}

\subsubsection{Variation regularity of $n$-alkanes in the sediment core}

T-ALK in sedimentary core varied from 0.04 to $0.86 \mu \mathrm{g} \mathrm{g}^{-1}$ (avg. $0.21 \mu \mathrm{g} \mathrm{g}^{-1}$ ) on a dry wt. basis (dw). The $n$-alkanes concentrations in the sediment core were compared with those in other regions of the world to

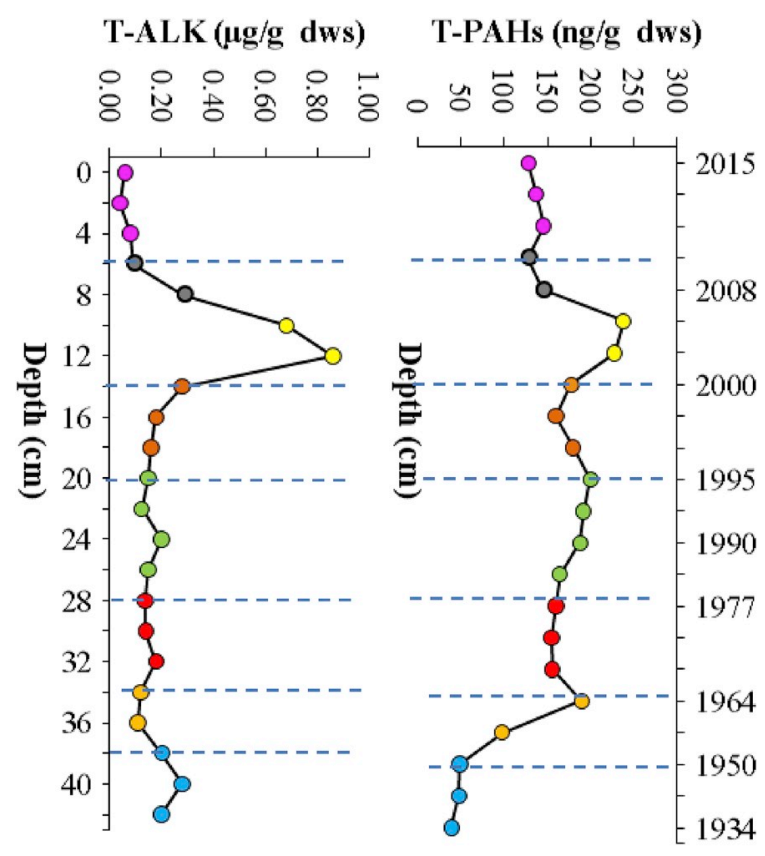

Fig. 4. Depth profile of total $n$-alkanes and PAHs concentrations in the sediment core from the Yellow River Estuary. (For interpretation of the references to colour in this figure legend, the reader is referred to the Web version of this article.)

assess the aliphatic hydrocarbons concentration in the YRE. T-ALK in the sedimentary core was similar to those measured in the marine sediments in the Fladen Ground, North Sea (0.025-0.49 $\mu \mathrm{g} \mathrm{g}^{-1}$; Ahmed et al., 2006). However, they were significantly lower than those in measured in the sedimentary cores from Macao Estuary, Pearl River (0.47-27.5 $\mu \mathrm{g} \mathrm{g}^{-1} \mathrm{dw}$; Kang et al., 2000), the Yellow Sea (0.70-15.80 $\mu \mathrm{g} \mathrm{g} \mathrm{g}^{-1} \mathrm{dw}$; Wu et al., 2001), Bohai Sea (1.22-8.35 $\mu \mathrm{g} \mathrm{g}^{-1} \mathrm{dw}$; Hu et al., 2011), and Chini Lake, Peninsular Malaysia (7-78 $\mu \mathrm{g} \mathrm{g}^{-1} \mathrm{dw}$; Bakhtiari et al., 2011). This comparison indicates that the concentrations of $n$-alkanes measured in the YRE sediment core are relatively low. Unlike the marine sediments, sediments from the Yellow River and Yellow River Estuary were mainly composed of sand and silt. The coarse-grained sediments (silt and sand) in the river and estuary had lower levels of T-ALK.

Prior to 1950, T-ALK concentrations remained below $0.28 \mu \mathrm{g} \mathrm{g}^{-1} \mathrm{dw}$, synchronous with the Second Sino-Japanese War (1937-1945) and the Chinese Civil War (1946-1949) (Fig. 4). During this period, many factories operated from the coastal areas to inner China in an effort to avoid the influence of war. Afterwards, T-ALK concentrations ranged from 0.13 to $0.20 \mu \mathrm{g} \mathrm{g}^{-1} \mathrm{dw}$, and fluctuated slightly from a depth of 38 to 14 $\mathrm{cm}$ (over the period from 1950 to 2000). Then, an abrupt increase in TALK concentrations was observed from a depth of 12 to $8 \mathrm{~cm}$ (over the period from 2000 to 2006), followed by a significant decrease to the top horizons of the core. High T-ALK levels may have been caused by the sustained economic development and further increase in energy consumption. Since 2006, increased usage of clean energy resources has led to a decrease in T-ALK concentrations.

\subsubsection{Estimation of terrigenous versus petrogenic inputs}

The $n$-alkane ranged in carbon numbers from $\mathrm{C}_{14}$ to $\mathrm{C}_{34}$ with a $\mathrm{C}_{\max }$ from 26 to 32, and the distribution of $n$-alkanes were similar to those of suspended particulate $n$-alkanes at the Lijin Hydrological Station of the Yellow River. The variation in LMH/HMW ratios with depth (or age) may reflect the overlapping effect of source input and burial deposition environment transformation. The source of organic matter in sediments cores of the YRE and Bohai Sea are basically controlled by the input of material from the Yellow River. Due to the larger particle size of suspended particulate matter from the Yellow River, the smaller organic 


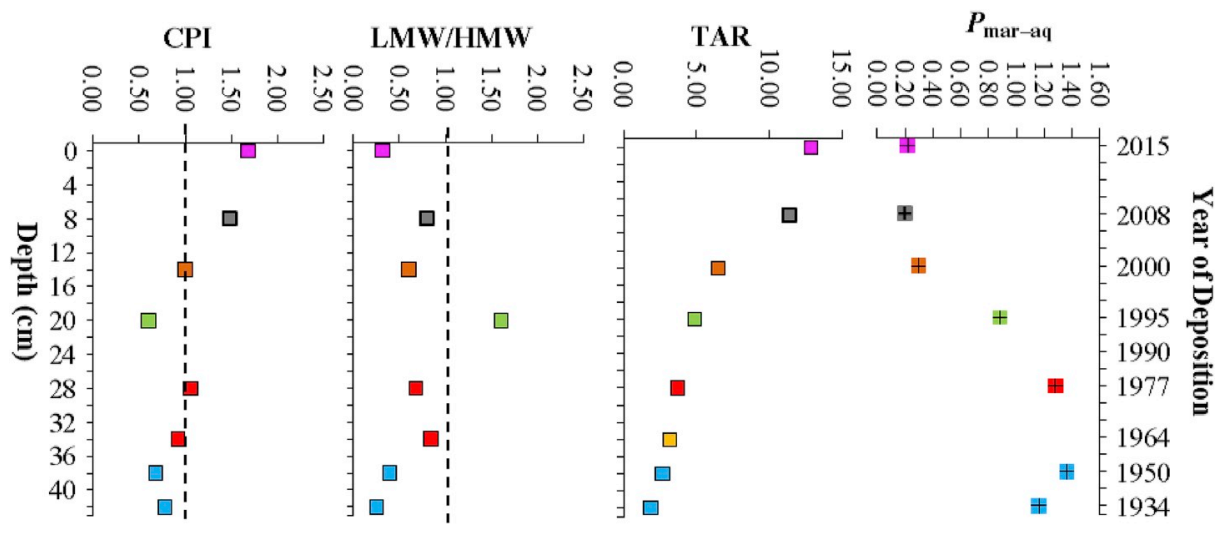

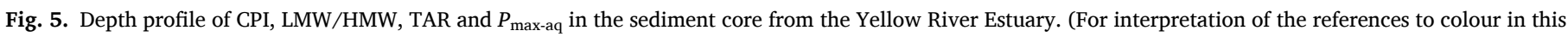
figure legend, the reader is referred to the Web version of this article.)

matter content, and the difficulty in preserving petroleum hydrocarbons, only selected samples from critical time nodes were submitted for GC-MS testing.

The CPI value of the studied samples was $1.14 \pm 0.41$ (Fig. 5), which is less than the parameter interval of typical terrestrial plant sources (4-10). This means that the source of $n$-alkanes is a mixture of terrestrial higher plants and marine algae. In addition, the impact of crude oil pollution cannot be ignored. The higher the CPI value, the greater the proportion of $n$-alkanes from terrestrial higher plants. In this study, the LMW/HMW values of most samples $(0.68 \pm 0.43)$ were lower than 1 , which is the characteristic of higher plant waxes (Fig. 5). The LMW/ HMW ratios and CPI values revealed a prominent terrestrial input to the suspended particles at the Lijin Hydrological Station (Zhang et al., 2009). Sedimentary records at Lijin Station are indicative of water and sediment discharges to the ocean. An increasing trend in the LMW/HMW ratio was observed over a period of half a century (42-26 cm depth, 1934-1990). In the 1960s, the Shengli Oilfield was discovered in the Yellow River Delta and exploited. Both the LMW/HMW ratio and CPI value were close to 1 from a depth of 32 to $29 \mathrm{~cm}$ (approximately 1964-1977), indicating a predominant petrogenic source. Hence, the increase in the LMW/HMW ratio could be ascribed to the petroleum hydrocarbon input after 1961. After 1978, the LMW/HMW ratio sharply increased from 0.68 to 1.88, and remained at this high level until 1995. This period is consistent with the fast economic development of China after the initiation of the "Reform and Open Policy" in 1978. Regarding the recent diversion of the Yellow River, the river was diverted in 1964 to run along the Diaokou into the sea. In 1976, in order to relocate its course from the Diaokou to the Qingshuigou, an artificial diversion was used and the Yellow River flowed into the Bohai Sea through the old YRE. The LMW/HMW ratio showed a decreasing trend from a depth of $22 \mathrm{~cm}$ to the top horizon of the core, which may be attributed to the stronger terrestrial influences caused by the channel diversion of the Yellow River in 1996. The variation in the CPI value is also attributed to Yellow River channel diversion.

\subsubsection{Estimation of terrigenous versus aquatic productivity}

This study showed a TAR ratio $>1$ for all studied locations, which affirmed the source of the $n$-alkanes as debris from terrestrial higher plants (Bourbonniere and Meyers, 1996). Low $P_{\text {mar-aq }}$ values $(0.01-0.3)$ correspond to terrestrial plants, mid-values $(\sim 0.4-0.6)$ to aquatic (freshwater and marine) emergent macrophytes including mangroves, and high values $(>0.6)$ to aquatic (freshwater and marine) submerged/floating macrophytes in coastal marine environments (e.g., Ficken et al., 2000; Kim et al., 2017). In order to estimate the terrigenous versus aquatic productivity of $n$-alkanes inputs, the samples at the above time nodes (1950, 1964, 1977, 1990, 1995, 2000, 2008, 2015) according to the analysis in section 3.2 , were analyzed separately. An increasing trend in TAR and a decreasing trend in $P_{\text {mar-aq }}$ were observed (Fig. 5). The inverse relation between TAR and $P_{\text {mar-aq }}$ demonstrates that terrigenous inputs predominated in the YRD (Fig. 3c), which can be explained by the proximity to the Yellow River providing high concentrations of terrigenous $n$-alkanes. A tremendous change in the trend occurred after 1996, which suggests that the channel diversion of the Yellow River that year had a great terrestrial influence. Conversely, the lower TAR value and higher $P_{\text {mar-aq }}$ value before 1976 reflect elevated marine productivity in the estuary.

\subsection{Distribution of PAHs in the sediment core and historical sedimentary record}

In our study, the concentrations of 16 USEPA priority PAHs (T-PAHs) ranged from 39.80 to $285.60 \mathrm{ng} \mathrm{g}^{-1} \mathrm{dw}$ with a mean of $153.97 \mathrm{ng} \mathrm{g}^{-1}$ dw. The overall variation observed in T-PAHs was similar to that observed for T-ALK (Fig. 4). Sharp increases in PAHs concentrations were observed 2000 years later. The T-PAHs concentrations observed in the present work are higher than those detected in sediment cores from the Bohai Sea (34.2-202 $\mathrm{ng} \mathrm{g}^{-1}$ and 53.6-186 $\mathrm{ng} \mathrm{g}^{-1} \mathrm{dw}$, Hu et al., 2011), and similar to those measured in sediment of the Pearl River Estuary, South China (59-330 $\mathrm{ng} \mathrm{g}^{-1} \mathrm{dw}$, Liu et al., 2005), but relatively higher than those reported for other regions of the world, such as Ohio, USA (621-11500 $\mathrm{ng} \mathrm{g}^{-1} \mathrm{dw}$, Li et al., 2001) and Curitiba, Brazil (39-2350 ng g ${ }^{-1} \mathrm{dw}$, Machado et al., 2014). The sediments from the Yellow River and Yellow River Estuary were mainly composed of sand and silt. The sediment clay content in sediments is one of the important factors that restricting the accumulation and distribution of PAHs in sediments. The coarse-grained sediments in the Yellow River Estuary had lower levels of T-PAHs.

PAHs diagnostic ratios have been used to distinguish diesel and gasoline combustion emission, different crude oil processing products and biomass burning processes (Yunker et al., 2002). PAHs diagnostic ratios should be used with caution, as their values may change during the environmental fate of these compounds (Kim et al., 2009; Tobiszewski and Namieśnik, 2012). To confirm the results obtained with these ratios, they could be supported by other molecular markers. By analyzing the fingerprint characteristics of PAHs in the sedimentary environment and studying the pollution characteristics and evolution process of PAHs in the marine environment with sedimentary records, the pollution history of PAHs in the region can be reconstructed. Prior to 1950, synchronous with the WWII (1937-1945) and the Chinese Civil War (1946-1949), the T-PAHs remained lower than $50 \mathrm{ng} \mathrm{g}^{-1} \mathrm{dw}$. From 1934 to 1950 , the PAHs pollution level was very small, which could basically represent the environmental background value of PAHs in the study area, i.e. the main source of PAHs was natural material input. From the $38 \mathrm{~cm}$, T-PAHs increased sharply to the first peak at the depth 


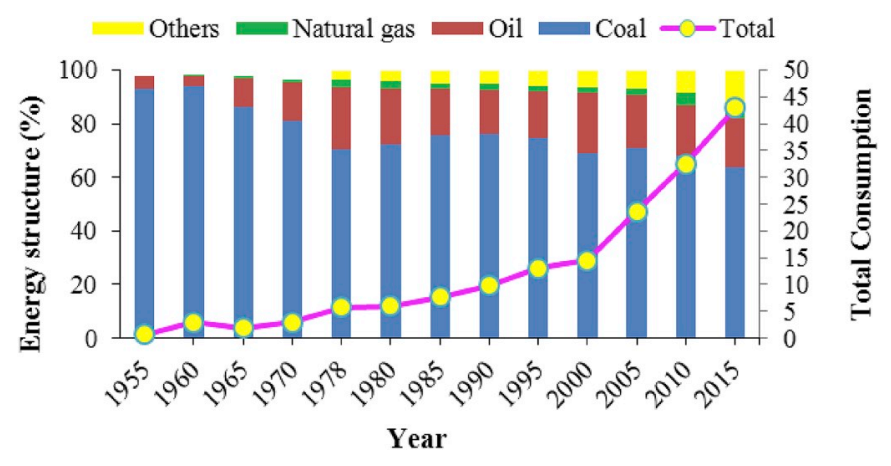

Fig. 6. Energy consumption and structure in China during 1955-2015.

Note: Total energy consumption refers to 100 million tons of standard coal; other energy includes Hydropower, Nuclear Power and Wind Power.

of $34 \mathrm{~cm}$, where the estimated date is nearly 1960s. In the 1960s, the Shengli Oilfield was discovered in the Yellow River Delta and exploited. The sharply increased T-PAHs may be caused by the oil spill in this oilfield exploitation.

PAHs are good indicators of human activities, and changes in their concentrations are closely related to regional energy consumption, industrialization levels and urbanization processes (Hu et al., 2011). From 1964 to 1978, T-PAHs showed a declining trend, which is synchronous with the Cultural Revolution in China (1966-1976). During this 10-year period, China was in a long-term recession and many factories were ceased because of political conflicts. The T-PAH profile from our study was similar to that reported for the Bohai Sea (Hu et al., 2011) and the Pearl River estuary (Liu et al., 2005). Similar to $n$-alkanes, T-PAHs gradually increased from 26 to $20 \mathrm{~cm}$ (approximately dated from 1978 to 1996). This period is also consistent with China's fast economic development following the "Reform and Open Policy" in 1978. From 1978 to 1995, China's total energy consumption increased from 5.71 to 13.12 billion tons of standard coal (Fig. 6). Rapid economic development in China is often coupled with a rapid increase in energy consumption. However, the T-PAHs decreased after 1996, despite a sustained economic growth in China, which may be due to the input of less organic matter and pollutants from the upper reaches caused by the channel diversion of the Yellow River in 1996. T-PAHs displayed a sharp increase over the last 8 years (between 2000 and 2008), largely due to the rapid economic development in this region, coupled with a rapid increase in energy consumption. Coal combustion emits a lot more PAHs than the combustion of oil products and natural gas. Since 2006, the increased usage of oil products, natural gas and other clean energy resources have caused a decrease in the proportion of coal in energy consumption (Fig. 6).

The ratios of some PAH monomers to parent compounds in sediments can be used to trace the potential sources of PAHs. Many studies have demonstrated that the petrogenic source PAHs mainly contain lower molecular weight (LMW) PAHs, while pyrogenic sources are abundant in high molecular weight (HMW) PAHs (Bouloubassi et al., 2012; Zakaria et al., 2002). Compared with light-molecular-weight PAHs (2-3 benzenoid rings), the relative abundance of the heavy-molecular-weight PAHs (4-6 benzenoid rings) showed an increasing trend from 1934 to 2015 (Fig. 7). This shift in the PAHs composition suggests more contributions from combustion. Furthermore, sources of PAHs can also be assessed by some ratios of specific molecular PAHs compounds, such as $\mathrm{BaA} /(\mathrm{BaA}+\mathrm{Chr})$ and IcdP/(IcdP + Bpe), etc (Yunker et al., 2002; Shi et al., 2007; Kanzari et al., 2014). A slight decrease in the Fla/(Fla + Pyr) and IcdP/(IcdP + Bpe) ratios after the 1970s confirms greater PAH inputs from petroleum combustion (Fig. 7). This period is consistent with an increase in the usage of oil and natural gas in Chinese energy consumption. Although there has been a significant increase in the consumption of petroleum products in China after 2000 , coal remains the major energy source for mainland China with $\sim 70 \%$ of its energy supply from coal combustion. As shown in Fig. 7, based on the coupling of isomeric ratios, PAHs in the sediment core were mainly sourced from coal and biomass combustion. An emission inventory for PAHs in China suggested that different activities involving fossil fuel consumption are as the dominant PAH emission source in China (Xu et al., 2006; Zhang et al., 2007). The results of this study are similar to those of previous studies (Wang et al., 2011, 2017; Yuan et al., 2014). Composition profiling of PAHs and molecular indices showed that the combustion of grass, wood and coal is the main source (Wang et al., 2011, 2017; Yuan et al., 2014), and that petroleum inputs also make a definite contribution to the PAHs in the soil and sediment, while petroleum inputs and petroleum combustion were the main PAH sources in surface water and groundwater ( $\mathrm{Li}$ and $\mathrm{Li}, 2017$ ).

\section{Conclusions}

The results showed a unimodal distribution of $n$-alkanes in SPM in the upper stream of the Yellow River, while a bimodal distribution was observed for the middle stream and lower river reaches. $n$-Alkanes in SPM from the Yellow River are mainly derived from mixed sources with dominant terrigenous inputs. The concentrations of $n$-alkanes in SPM increased from $3.51 \mu \mathrm{g} \mathrm{L}^{-1}$ to $7.57 \mu \mathrm{g} \mathrm{L}^{-1}$ from upstream to downstream in the Yellow River.

The T-ALK and T-concentrations in the sediment core ranged from

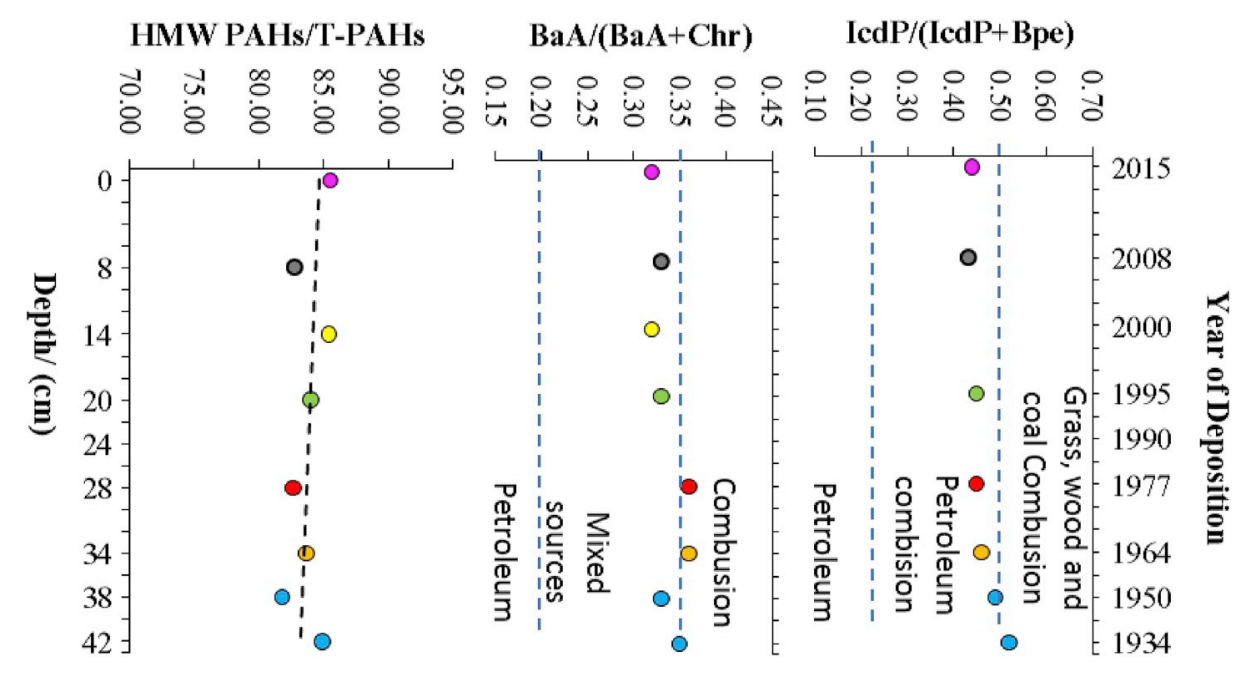

Fig. 7. Depth profile of total LMW/HMW, BaA/(BaA $+\mathrm{Chr})$ and IcdP/(IcdP + Bpe $)$ in the sediment core from the YRE. 
0.04 to $0.86 \mu \mathrm{g} \mathrm{g}^{-1} \mathrm{dw}$ (avg. $0.21 \mu \mathrm{g} \mathrm{g}^{-1} \mathrm{dw}$ ) and from 0.04 to $0.29 \mu \mathrm{g}$ $\mathrm{g}^{-1} \mathrm{dw}$ (avg. $0.15 \mu \mathrm{g} \mathrm{g}^{-1} \mathrm{dw}$ ), respectively. The variation in LMW/HMW ratios and CPI with depth (or age) reflects the overlapping effect of source input and burial transformation. The inverse relation between TAR and $P_{\text {mar-aq }}$ demonstrates that terrigenous input predominates in the YRE, which can be explained by the proximity of the Yellow River, which provides high concentrations of terrigenous $n$-alkanes. The results are consistent with those reflected by $n$-alkanes in SPM. PAHs are predominantly derived from coal and biomass combustion, whereas the contribution of petroleum combustion slightly increased after the 1970s, synchronous with the increasing usage of oil and gas in China. The PAHs profile in the sediment core presents a good correlation with the Chinese socioeconomic conditions during the period of 1934-2015, confirming that PAHs are a sensitive tracer for anthropogenic activity.

\section{Declaration of competing interest}

The authors declare that they have no known competing financial interests or personal relationships that could have appeared to influence the work reported in this paper.

\section{Acknowledgements}

This study was co-supported by Key Projects in the Yantai Science \& Technology Pillar Program (2018ZHGY079), Shandong Key R\&D Program (Public Welfare Project) (2019GSF109081); and Science and Technology Service Network Initiative, Chinese Academy of Sciences (KFJ-EW-STS-127).

\section{Appendix A. Supplementary data}

Supplementary data to this article can be found online at https://doi. org/10.1016/j.apgeochem.2019.104475.

\section{References}

Ahmed, A.S., Webster, L., Pollard, P., Davies, I.M., Russell, M., Walsham, P., Packer, G., Moffat, C.F., 2006. The distribution and composition of hydrocarbons in sediments from the Fladen Ground, North Sea, an area of oil production. J. Environ. Monit. 8 307-316.

Ankit, Y., Mishra, P.K., Kumar, P., Jha, D.K., Kumar, V.V., Ambili, V., Anoop, A., 2017 Molecular distribution and carbon isotope of $n$-alkanes from Ashtamudi Estuary, South India: assessment of organic matter sources and paleoclimatic implications. Mar. Chem. 196, 62-70.

Bakhtiari, A.R., Zakaria, M.P., Yaziz, M.I., Lajis, M.N.H., Bi, X., 2011. Variations and origins of aliphatic hydrocarbons in sediment cores from Chini Lake in Peninsular Malaysia. Environ. Forensics 12, 79-91.

Bourbonniere, R.A., Meyers, P.A., 1996. Sedimentary geolipid records of historical changes in the watersheds and productivities of Lakes Ontario and Erie. Limnol. Oceanogr. 41, 352-359.

Boitsov, S., Jensen, H.K.B., Klungsøyr, J., 2009. Natural background and anthropogenic inputs of polycyclic aromatic hydrocarbons (PAH) in sediments of South-Western Barents Sea. Mar. Environ. Res. 68 (5), 236-245.

Bouloubassi, I., Roussiez, V., Azzoug, M., Lorre, A., 2012. Sources, dispersal pathways and mass budget of sedimentary polycyclic aromatic hydrocarbons (PAH) in the NW Mediterranean margin, Gulf of Lions. Mar. Chem. 142-144, 18-28.

Bush, R.T., McInerney, F.A., 2013. Leaf wax $n$-alkane distributions in and across modern plants: implications for paleoecology and chemotaxonomy. Geochem. Cosmochim. Acta $117,161-179$.

Chen, J., Makoto, T., Liu, G.Q., Yoshihiro, F., 2007. Nitrate pollution of groundwater in the Yellow River delta, China. Hydrogeol. J. 15, 1605-1614.

Ficken, K.J., Li, B., Swain, D.L., Eglinton, G., 2000. An n-alkane proxy for the sedimentary input of submerged/floating freshwater aquatic macrophytes. Org. Geochem. 31, 745-749.

Hedges, J.I., Prahl, F.G., 1993. Early diagenesis: consequences for applications of molecular biomarkers. In: Engel, M.H., Macko, S.A. (Eds.), Organic Geochemistry: Principles and Applications. Plenum Press, New York, pp. 237-253.
Hu, L., Guo, Z., Shi, X., Qin, Y., Lei, K., Zhang, G., 2011. Temporal trends of aliphatic and polyaromatic hydrocarbons in the Bohai Sea, China: evidence from the sedimentary record. Org. Geochem. 42, 1181-1193.

Kaiser, J., Ruggieri, N., Hefter, J., Siegel, H., Mollenhauer, G., Arz, H.W., Lamy, F., 2014. Lipid biomarkers in surface sediments from the Gulf of Genoa, Ligurian sea (NW Mediterranean sea) and their potential for the reconstruction of palaeoenvironments. Deep-Sea Res. Part I Oceanogr. Res. Pap. 89, 68-83.

Kang, Y.H., Sheng, G.Y., Fu, J.M., Mai, B.X., Zhang, G., Lin, Z., Niu, Y.S., 2000. The study of $n$-alkane in a sedimentary core from Macao Estuary, Pearl River. Geochemical 29, 302-1310.

Kanzari, F., Syakti, A.D., Asia, L., Malleret, L., Piram, A., Mille, G., Doumenq, P., 2014. Distributions and sources of persistent organic pollutants (aliphatic hydrocarbons, PAHs, PCBs and pesticides) in surface sediments of an industrialized urban river (Huveaune), France. Sci. Total Environ. 478, 141-151.

Kim, D., Kumfer, B.M., Anastasio, C., Kennedy, I.M., Young, T.M., 2009. Environmental ageing of polycyclic aromatic hydrocarbons on soot and its effect on source identification. Chemosphere 76, 1075-1081.

Kim, J.H., Lee, D.H., Yoon, S.H., Jeong, K.S., Choi, B., Shin, K.H., 2017. Contribution of petroleum-derived organic carbon to sedimentary organic carbon pool in the eastern Yellow Sea (the northwestern Pacific). Chemosphere 168, 1389-1399.

Li, K., Christensen, E.R., Camp, R.P., Imamoglu, I., 2001. PAHS in dated sediments of Ashtabula River, Ohio, USA. Environ. Sci. Technol. 35, 2896-2902.

Li, J., Li, F.D., 2017. Polycyclic aromatic hydrocarbons in the Yellow River estuary: levels, sources and toxic potency assessment. Mar. Pollut. Bull. 116, 479-487.

Liu, G.Q., Zhang, G., Li, X.D., Li, J., Peng, X.Z., 2005. Sediment record of polycyclic aromatic hydrocarbons in a sediment core from the Pearl River Estuary, South Chian. Mar. Pollut. Bull. 51, 912-921.

Machado, K.S., Figueira, R.C.L., Côcco, L.C., Froehner, S., Fernandes, C.V.S., Ferreira, P. A.L., 2014. Sedimentary record of PAHs in the Barigui River and its relation to the socioeconomic development of Curitiba, Brazil. Sci. Total Environ. 482-483, 42-52.

Middelburg, J.J., Herman, P.M., 2007. Organic matter processing in tidal estuaries. Mar. Chem. 106, 127-147.

Nemr, A. El, Moneer, A.A., Ragab, S., Sikaily, A.E.I., 2016. Distribution and sources of $n$ alkanes and polycyclic aromatic hydrocarbons in shellfish of the Egyptian Red Sea coast. Egypt. J. Aquat. Res. 42, 121-131.

Shi, Z., Tao, S., Pan, B., Liu, W.X., Shen, W.R., 2007. Partitioning and source diagnostics of polycyclic aromatic hydrocarbons in rivers in Tianjin, China. Environ. Pollut. 146, 492-500.

Tobiszewski, M., Namieśnik, J., 2012. PAH diagnostic ratios for the identification of pollution emission sources. Environ. Pollut. 162, 110-119.

Thornton, S.F., McManus, J., 1994. Application of organic carbon and nitrogen stable isotope and $\mathrm{C} / \mathrm{N}$ ratios as source indicators of organic matter provenance in estuarine systems: evidence from the Tay Estuary. Scotland. Estuar. Coast. Shelf Sci. 38, 219-223.

Wang, C.Y., Wang, W.C., He, S.J., Du, J.G., Sun, Z.G., 2011. Sources and distribution of aliphatic and polycyclic aromatic hydrocarbons in Yellow River delta nature reserve, China. Appl. Geochem. 26, 1330-1336.

Wang, C.Y., Lv, Y.C., Li, Y.W., 2018. Riverine input of organic carbon and nitrogen in water-sediment system from the Yellow River estuary reach to the coastal zone of Bohai Sea, China. Cont. Shelf Res. 157, 1-9.

Wang, S.S., Liu, G.J., Y, Z.J., Da, C.N., 2017. Distribution, origin, and characteristics of $n$ alkanes in surface soils from the Yellow River Delta natural reserve, China. Soil Sci. Soc. Am. J. 81, 915-922.

Wu, X., Bi, N., Kanai, Y., Saito, Y., Zhang, Y., Yang, Z., Fan, D., Wang, H., 2015. Sedimentary records off the modern Huanghe (Yellow River) delta and their response to deltaic river channel shifts over the last 200 years. J. Asian Earth Sci. 108, 68-80.

Wu, Y., Zhang, J., Mi, T.Z., Li, B., 2001. Occurrence of n-alkanes and polycyclic aromatic hydrocarbons in the core sediments of the Yellow Sea. Mar. Chem. 76, 1-15.

Xu, S.S., Li, W.X., Tao, S., 2006. Emission of polycyclic aromatic hydrocarbons in China. Environ. Sci. Technol. 40, 702-708.

Yang, Z.F., Niu, J.F., Wang, L.L., Wang, J.Y., Shen, Z.Y., 2009. Pollution assessment and source identifications of polycyclic aromatic hydrocarbons in sediments of the Yellow River Delta, a newly born wetland in China. Environ. Monit. Assess. 158, 561-571.

Yuan, H.M., Li, T.G., Ding, X.G., Zhai, G.M., Ye, S.Y., 2014. Distribution, sources and potential toxicological significance of polycyclic aromatic hydrocarbons (PAHs) in surface soils of the Yellow River Delta, China. Mar. Pollut. Bull. 83, 258-264.

Yunker, M.B., Macdonald, R.W., Vingarzan, R., Mitchell, R.H., Goyette, D., Sylvestre, S., 2002. PAHs in the Fraser River basin: a critical appraisal of PAH ratios as indicators of PAH source and composition. Org. Geochem. 33, 489-515.

Zakaria, M.P., Takada, H., Tsutsumi, S., Ohno, K., Yamada, J., Kouno, E., Kumata, H., 2002. Distribution of polycyclic aromatic hydrocarbons (PAHs) in rivers and estuaries in Malaysia: a widespread input of petrogenic PAHs. Environ. Sci. Technol. 36 (9), 1907-1918.

Zhang, L.J., Zhang, J., Gong, M.N., 2009. Size distributions of hydrocarbons in suspended particles from the Yellow River. Appl. Geochem. 24, 1168-1174.

Zhang, Y.X., Tao, S., Cao, J., Coveney, R.M., 2007. Emission of polycyclic aromatic hydrocarbons in China by county. Environ. Sci. Technol. 41, 683-687. 